\title{
Influence of low spatial resolution a priori data on tropospheric $\mathrm{NO}_{2}$ satellite retrievals
}

\author{
A. Heckel ${ }^{1,2}$, S.-W. Kim ${ }^{3,4}$, G. J. Frost ${ }^{3,4}$, A. Richter ${ }^{1}$, M. Trainer ${ }^{3}$, and J. P. Burrows ${ }^{1}$ \\ ${ }^{1}$ Institute of Environmental Physics and Institute of Remote Sensing, University of Bremen, Bremen, Germany \\ ${ }^{2}$ Department of Geography, Swansea University, Swansea, UK \\ ${ }^{3}$ NOAA Earth System Research Laboratory, Chemical Sciences Division, 325 Broadway, R/CSD4, CO 80305, Boulder, USA \\ ${ }^{4}$ Cooperative Institute for Research in Environmental Sciences, University of Colorado, CO 80309, Boulder, USA
}

Received: 5 February 2011 - Published in Atmos. Meas. Tech. Discuss.: 18 March 2011

Revised: 24 August 2011 - Accepted: 30 August 2011 - Published: 9 September 2011

\begin{abstract}
The retrieval of tropospheric columns of $\mathrm{NO}_{2}$ and other trace gases from satellite observations of backscattered solar radiation relies on the use of accurate a priori information. The spatial resolution of current space sensors is often significantly higher than that of the a priori datasets used, introducing uncertainties from spatial misrepresentation. In this study, the effect of spatial under-sampling of a priori data on the retrieval of $\mathrm{NO}_{2}$ columns was studied for a typical coastal area (around San Francisco). Highresolution $\left(15 \times 15 \mathrm{~km}^{2}\right) \mathrm{NO}_{2}$ a priori data from the WRFChem model in combination with high-resolution MODIS surface reflectance and aerosol data were used to investigate the uncertainty introduced by applying a priori data at typical global chemical transport model resolution. The results show that the relative uncertainties can be large (more than a factor of 2 if all a priori data used is at the coarsest resolution) for individual measurements, mainly due to spatial variations in $\mathrm{NO}_{2}$ profile and surface albedo, with smaller contributions from aerosols and surface height changes. Similar sensitivities are expected for other coastal regions and localised sources such as power plants, highlighting the need for highresolution a priori data in quantitative analysis of the spatial patterns retrieved from satellite observations of tropospheric pollution.
\end{abstract}

\section{Introduction}

Nitrogen oxides in general, and nitrogen monoxide (NO) and nitrogen dioxide $\left(\mathrm{NO}_{2}\right)$ in particular, are key species in tropospheric chemistry. Due to their rapid conversion, $\mathrm{NO}$ and $\mathrm{NO}_{2}$ are coupled and usually referred to as $\mathrm{NO}_{\mathrm{x}}$, that is a

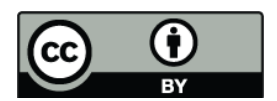

Correspondence to: A. Richter (richter@iup.physik.uni-bremen.de) major precursor of tropospheric ozone $\left(\mathrm{O}_{3}\right)$ and a source of nitric acid and particulate nitrates. Obtaining knowledge of the global distribution of $\mathrm{NO}_{\mathrm{x}}$ and estimating the strength of its various sources and sinks are essential to improve our understanding of tropospheric chemistry. Valuable information on $\mathrm{NO}_{\mathrm{x}}$ levels and their temporal evolution is provided by routinely performed ground-based measurements both in polluted environments and at remote stations. Aircraft campaigns complement these measurements by adding vertical information and facilitating process studies of the chemical transformations taking place within air masses as they are transported. However, such observations and datasets are highly localised. As a result of having numerous sources with highly variable emission strengths and a variable, but generally short, atmospheric lifetime, the global spatial distribution of $\mathrm{NO}_{\mathrm{x}}$ is inhomogeneous and not well captured from a sparse network of ground-based measurements and aircraft campaigns. In order to obtain global knowledge of short-lived chemical species, remote sensing from satellite platforms offers significant advantages. Global maps of tropospheric $\mathrm{NO}_{2}$ columns have been available since 1996 from data collected by several satellite-borne instruments, including the Global Ozone Monitoring Experiment, GOME (Burrows et al., 1999), Scanning Imaging Absorption Spectrometer for Atmospheric Chartography, SCIAMACHY (Bovensmann et al., 1999), GOME-2 (Callies et al., 2004) and Ozone Monitoring Experiment, OMI (Levelt et al., 2006). While the spatial resolution of the GOME measurements is limited $\left(40 \times 320 \mathrm{~km}^{2}\right)$, data from the more recent instruments SCIAMACHY, GOME-2 and OMI have improved horizontal spatial resolution of up to $13 \times 12 \mathrm{~km}^{2}$ (see Table 1), which can better resolve the high spatial variability of $\mathrm{NO}_{\mathrm{x}}$.

The tropospheric columns of $\mathrm{NO}_{2}$ derived from satellite data have been used to investigate important aspects of $\mathrm{NO}_{\mathrm{x}}$ emissions and atmospheric chemistry, including weekly cycles (Beirle et al., 2003; Kim et al., 2009; Russell et al.,

Published by Copernicus Publications on behalf of the European Geosciences Union. 
Table 1. Current satellite instruments used for tropospheric $\mathrm{NO}_{2}$ measurements and their respective spatial resolution. Spatial zoom modes are given in parentheses. OMI pixel sizes depend on the relative position within the OMI swath.

\begin{tabular}{ll}
\hline Instrument & Pixel Size $($ across $\times$ along track $)\left[\mathrm{km}^{2}\right]$ \\
\hline GOME & $320 \times 40(15 \times 40)$ \\
SCIAMACHY & $60 \times 30(30 \times 30)$ \\
OMI & $24 \times 13$ to $160 \times 28(12 \times 13)$ \\
GOME-2 & $80 \times 40(13 \times 40)$ \\
\hline
\end{tabular}

2010), trends attributed to changes in emissions (Richter et al., 2005; van der A et al., 2006, 2008; Kim et al., 2006, 2009), power plant emissions (Kim et al., 2006, 2009), ship emissions (Beirle et al., 2004; Richter et al., 2004; Franke et al., 2009), $\mathrm{NO}_{\mathrm{x}}$ emissions from soils (Bertram et al., 2005) and diurnal changes in $\mathrm{NO}_{2}$ (Boersma et al., 2008). In order to achieve the necessary significance in terms of signal-tonoise and spatial sampling, averages over longer time periods or larger regions have been used in most studies. Satellite retrievals are also used in inversion models to assess $\mathrm{NO}_{\mathrm{x}}$ emissions (top-down approach) (e.g. Martin et al., 2003, 2006; Blond et al., 2007; Konovalov et al., 2008). These applications rely on quantitative analysis with high absolute accuracy on the measurements to derive reasonable emissions estimates. In all of the above applications, a good error characterisation is needed for the interpretation of the satellite retrievals.

The retrieval of tropospheric $\mathrm{NO}_{2}$ from satellite observations of scattered sunlight is based on the analysis of the trace gas absorption signatures using the DOAS (Differential Optical Absorption Spectroscopy) approach. The obtained slant columns (SCs), i.e. the column amount of the trace gas integrated along all the light paths contributing to the signal, are separated into a stratospheric and a tropospheric contribution. The resulting tropospheric SCs are converted into tropospheric vertical columns (VCs) using an airmass factor (AMF) that is based on model calculations of the radiative transfer in the atmosphere.

$\mathrm{VC}=\frac{\mathrm{SC}}{\mathrm{AMF}}$

$\mathrm{AMF}=\frac{1}{\mathrm{VCD}_{\text {apriori }}} \sum_{z=1}^{N} \mathrm{bAMF}_{z} \cdot \mathrm{TC}_{z} \cdot n_{z} \cdot \Delta z$

The AMF for a given scenario is usually determined from pre-calculated, altitude-dependent box airmass factors bAMF $_{z}$ for an altitude range $\Delta z$, the a priori vertical $\mathrm{NO}_{2}$ concentration profile $n_{z}$, and the corresponding vertical column VCD apriori. The temperature dependence of the $\mathrm{NO}_{2}$ cross-section is often also corrected in this step by including a temperature correction factor $\mathrm{TC}_{z}$ (Boersma et al., 2004).
Calculation of the box airmass factors critically relies on the use of appropriate a priori datasets (e.g. surface albedo, $\mathrm{NO}_{2}$ profile shape, aerosol loading, terrain pressure) needed for proper description of the radiative properties of the atmosphere at the time of the measurement. Typically for global retrievals this information is available at a spatial resolution between $0.25-1^{\circ}$ (albedo) and 2-3 $3^{\circ}$ (profile shape).

Recent uncertainty estimates, using comparisons with ground-based and aircraft validation data, suggest that currently used retrievals perform well but considerable scatter is found when comparing the satellite data to independent observations (e.g. Ordóñez et al., 2006; Martin et al., 2006; Celarier et al., 2008; Boersma et al., 2009; Hains et al., 2010). Several factors contribute to the overall uncertainty of the satellite retrievals, including measurement noise and the uncertainty in the a priori information used (e.g. absorption cross-sections, aerosol optical thickness, clouds, profile shape of aerosol and $\mathrm{NO}_{2}$ ). While the former has a random nature and can be reduced by averaging, the latter contains systematic components and is only in part reduced by averaging. As noted above, the spatial resolution of the measurements has increased as a result of instrument development (see Table 1 for a list of currently available sensors and their spatial resolutions), but the resolution of the a priori datasets used in the retrievals has not always been improved from that used for GOME-1, in particular with respect to $\mathrm{NO}_{2}$ profiles. As already pointed out in Boersma et al. (2007), this inappropriate spatial resolution of the a priori datasets is a source of additional uncertainties.

In this study, the uncertainty of the retrieved $\mathrm{NO}_{2} \mathrm{VC}$ introduced by the coarse spatial resolution of the a priori data used for AMF calculations will be investigated in detail. More specifically, the impact of spatial variability of the $\mathrm{NO}_{2}$ profile shape, surface albedo and aerosol loading on the AMF for $\mathrm{NO}_{2}$ satellite retrievals is evaluated for three different horizontal scales: $270 \mathrm{~km}, 90 \mathrm{~km}$ and $15 \mathrm{~km}$. This is accomplished by analysing the distribution of AMFs within a domain having approximately the size of a typical global chemical transport model (CTM) grid cell used in previous studies. The a priori $\mathrm{NO}_{2}$ profiles used are taken from simulations by the regional Weather Research and Forecasting Chemistry model (WRF-Chem). Albedo and aerosol a priori data are taken from the moderate resolution imaging spectroradiometer (MODIS) retrievals. The analysis is focused on a single clear summer day (29 August 2005) over the San Francisco area (in California, US) because a cloud-free scenario is important to simplify the radiative transfer calculation and the interpretation of the results. In addition, we tested the results against a set of monthly mean AMFs to show that the main conclusions are robust and not dependent on the choice of a particular day.

In order to investigate the impact of heterogeneity of tropospheric conditions on the retrieval of tropospheric $\mathrm{NO}_{2}$ columns, the domain used in this study was chosen to show large variability in the parameters to be investigated, namely 

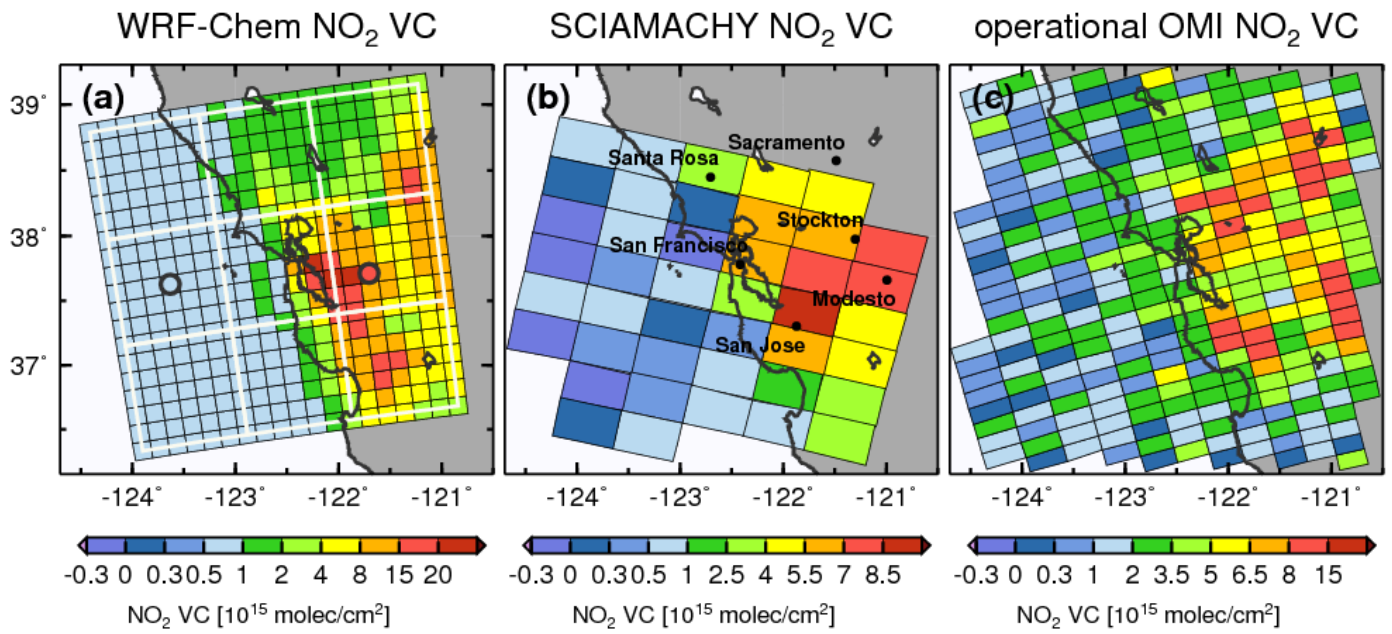

Fig. 1. (a) Map of the domain showing tropospheric $\mathrm{NO}_{2}$ columns as calculated by the WRF-Chem model at $15-\mathrm{km}$ resolution for $29 \mathrm{Au}-$ gust 2005. The white lines indicate the sub-domains discussed in the text. The two open circles are the location of the profiles shown in Fig. 2. (b) Tropospheric $\mathrm{NO}_{2}$ columns retrieved from SCIAMACHY data (University of Bremen). (c) $\mathrm{OMI}_{\text {I }}$ tropospheric $\mathrm{NO}_{2}$ columns (NASA Level 2 Collection 3 product). The satellite data clearly show the existing heterogeneity of the tropospheric $\mathrm{NO}_{2}$ field. Differences are primarily a result of different assumptions in the retrieval as well as differences in spatial resolution and time of satellite overpass.

$\mathrm{NO}_{2}$ profile shape, albedo and aerosol optical thickness (AOT). The area around San Francisco on the west coast of the US provides such a domain and is shown in Fig. 1. In general, areas close to coastlines show high variability in surface and emission patterns and also in the $\mathrm{NO}_{\mathrm{x}}$ sinks. Such regions therefore are expected to be more difficult for retrievals using backscattered radiation observed from orbiting satellites. Although the choice of a heterogeneous coastal region was intentionally made for its high variability, such areas are of particular significance as $37 \%$ of the world's population live within $100 \mathrm{~km}$ of coastlines (Cohen et al., 1997), and this percentage continues to increase. Overall, our understanding of the accuracy and assumptions used in the retrieval of tropospheric $\mathrm{NO}_{2}$ for coastal regions are of specific interest and particular importance for global air pollution studies.

In this study, a single cloud-free day in summer (29 August 2005) is the focus. The aim is to get an estimate of the impact of variability in a priori parameters on the retrieved $\mathrm{NO}_{2}$ columns for a single test case. By selecting a summer day with high sun, the sensitivity of airmass factors to the a priori parameters is less than the more complex cases found in winter in mid and high latitudes when low sun, clouds, and potentially snow cover on the surface introduce further complications. The choice of date was more or less arbitrary and fell to this specific day because it was cloud-free over ocean and land, which is not often the case in the region.

In current datasets of $\mathrm{NO}_{2}$ tropospheric columns, the retrieval algorithms often use only a limited set of a priori parameters to compute the AMFs for all the measurements taken in the region selected for this study (Fig. 1). Small scale variations in measurement sensitivity are therefore not well represented. In this investigation, AMFs have been calculated for each 15-km box shown in Fig. 1a and, for comparison, also for each 90-km box. We compare these results to the average of the $15-\mathrm{km}$ AMFs across the entire scene. Additionally, a single AMF is calculated using the average of the $\mathrm{NO}_{2}$ profiles at $15 \mathrm{~km}$ resolution.

\section{Model and data description}

The size of the area of our study is $270 \times 270 \mathrm{~km}^{2}$, which is approximately $2.8^{\circ}$ latitude by $3.5^{\circ}$ longitude. These values are of the same order of magnitude as the horizontal resolution of the CTMs currently used to provide a priori $\mathrm{NO}_{2}$ profiles for the retrieval of $\mathrm{NO}_{2}$ from satellite measurements (Martin et al., 2003; Richter et al., 2005; Boersma et al., 2007). The study area encompasses nine boxes of 90km-resolution and 361 boxes of $15-\mathrm{km}$ resolution. For both spatial resolutions, the regional WRF-Chem model was run to provide vertical $\mathrm{NO}_{2}$ profiles. An overview of the domain and the $\mathrm{NO}_{2}$ column distribution present in the scene is shown in Fig. 1a. As expected, the scene contains a large heterogeneity in the $\mathrm{NO}_{2}$ distribution. The western half of the domain covers a region of clean oceanic air having very small tropospheric $\mathrm{NO}_{2}$ columns. In the northern part of the domain, rural regions dominate with columns between $1 \times 10^{15}$ and $2 \times 10^{15} \mathrm{molec} \mathrm{cm}^{-2}$. The rest of the eastern half of the domain is representative of urban pollution from San Francisco, Oakland, San Jose, Sacramento, Stockton, and Modesto. This kind of spatial variability can clearly be resolved on a daily basis by current space-borne sensors such as SCIAMACHY (Fig. 1b) or OMI (Fig. 1c). However, it 
is not represented if a priori information is used at a spatial resolution typical for current CTMs which provide only one average profile for the whole scene. The aim of this sensitivity study is the analysis of the uncertainties introduced by this mismatch of the spatial resolution in a priori information and the real variability. For this, several simplified scenarios are investigated which are not meant to represent current retrievals and their strengths and weaknesses, but rather aim at evaluating the basic principles and connections using an extreme situation.

\subsection{Input data for radiative transfer calculations}

As mentioned above, the sensitivity of the satellite measurements to the $\mathrm{NO}_{2}$ present in the atmosphere is usually expressed as an airmass factor, defined as the ratio between the $\mathrm{NO}_{2}$ slant column retrieved from the spectral fit of the backscattered radiation for a particular viewing geometry to the vertical column present in the atmosphere. For a cloudfree situation, this ratio depends mainly on the viewing geometry, the position of the sun, the vertical distribution of $\mathrm{NO}_{2}$ (but not its absolute amount), the surface altitude and reflectance, and the aerosol loading. In order to test the sensitivity of the AMF to the various parameters, input data are needed at sufficient spatial resolution for all of the quantities listed. AMFs are computed here by the radiative transfer model SCIATRAN (Rozanov et al., 2005), which includes full treatment of multiple scattering and aerosols. The viewing geometry was selected to be nadir and the solar zenith angle (SZA) to be $35^{\circ}$, a typical value for SCIAMACHY measurements in August at this latitude. The $\mathrm{NO}_{2}$ vertical profiles and surface elevation were taken from two simulations by the WRF-Chem model, and the surface reflectance and aerosol load come from MODIS measurements as described in Sect. 2.3. The WRF-Chem model terrain height is based on the US Geological Survey 30 arc s (approximately $1 \mathrm{~km}$ ) elevation data. The atmospheric pressure and temperature profiles for these radiative transfer calculations are combined profiles of WRF-Chem for the troposphere continued by the US standard atmosphere above the model tropopause.

\subsection{WRF-Chem model}

The WRF-Chem model (Grell et al., 2005) was used to obtain the $\mathrm{NO}_{2}$ vertical profiles at different horizontal resolutions. The model carried out on-line simulation of chemistry and aerosol processes in the western US with $15 \times 15 \mathrm{~km}^{2}$ and $90 \times 90 \mathrm{~km}^{2}$ horizontal resolutions. Meteorological initial and boundary conditions are taken from the National Centers for Environmental Prediction Global Forecast System model. The model default idealized chemical soundings (Grell et al., 2005; McKeen et al., 2005) were used as initial and boundary conditions of chemical species. The emissions are based on the US Environmental Protection Agency's National Emission Inventory 1999 and the Biogenic Emission Inventory
System (BEIS 3.11) algorithm. The $\mathrm{NO}_{2}$ emissions from power plants were updated using monthly mean Continuous Emission Monitoring System data for 2005 (Frost et al., 2006). The chemical mechanism used is the RACM-ESRL (Kim et al., 2009). The details of physical and chemical options selected are summarized in Kim et al. (2009). For this study, the WRF-chem model fields were sampled according to the typical satellite overpass time at 19:00 UTC.

\subsection{Surface spectral reflectance and aerosol optical thickness from MODIS data}

The MODIS black sky albedo level 3 product (Schaaf et al., 2002; Salomon et al., 2006) has been used as the surface spectral reflectance in this study. The collection 5 data product combines data from both instruments on the Terra and Aqua satellite to the so-called MCD43C 3 product (http://modis-land.gsfc.nasa.gov/brdf.htm). This dataset is provided as a global equal-angle grid of $0.05^{\circ}$ resolution and was binned according to our domain grid. The black sky albedo product is composed of a 16-day average of the MODIS reflectance measurements. Here the values based on the measurements from 21 August to 5 September 2005 are used. We applied data from MODIS channel 3 (459$479 \mathrm{~nm}$ ), which is close to the spectral range typically used for $\mathrm{NO}_{2}$ retrievals $(425-450 \mathrm{~nm})$. As MODIS albedo data is only given over land, we assumed a constant spectral reflectance of 0.04 over water.

For the aerosols, the aerosol type, vertical distribution and aerosol optical thickness are needed as input for the radiative transfer. For simplicity, we assumed an average continental external mixture (OPAC; Hess et al., 1998) confined in the lowermost $1 \mathrm{~km}$ of the atmosphere in a well-mixed boundary layer throughout the domain. The AOT is taken from MODIS analysis (Levy et al., 2007a,b) by gridding the level 2 product to a $0.05^{\circ}$ grid and subsequently binning it to $15 \mathrm{~km}$ and $90 \mathrm{~km}$, respectively, to match our domain grid. All data from August 2005 were used to obtain a representative field of the variability of the AOT. The MODIS analysis provides AOT at the same wavelength as the albedo data $(465 \mathrm{~nm})$, but only over land. Over water we used a constant AOT of 0.1.

\section{Results}

\subsection{AMF sensitivity to $\mathrm{NO}_{2}$ profiles}

The dependence of the AMF on the $\mathrm{NO}_{2}$ profiles is first investigated. The albedo is kept constant at 0.04 and no aerosol is considered in the AMF calculations. The average $\mathrm{NO}_{2}$ profile for the domain, taken as the mean of all 361 individual profiles, is shown in Fig. 2. Its shape is typical for a situation influenced by pollution, and is characterized by a wellmixed boundary layer of about $1 \mathrm{~km}$ height and a smooth transition to low values in the free troposphere. For comparison, a polluted profile, also shown in Fig. 2, has a much 


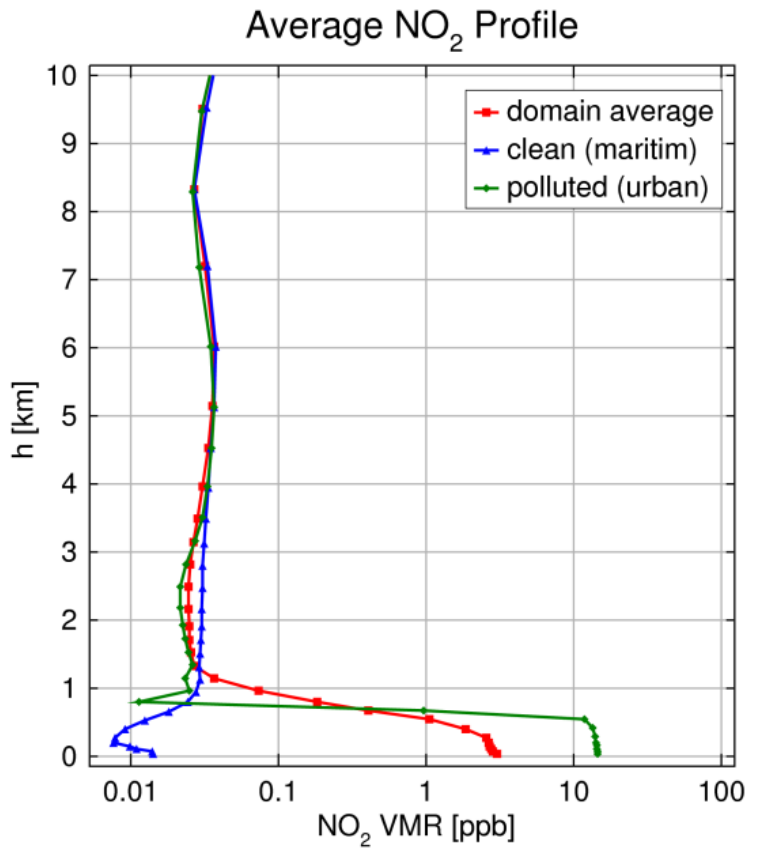

Fig. 2. The average WRF-Chem $\mathrm{NO}_{2}$ profile of the domain (shown in red) together with a typical maritime profile (blue) and a typical polluted profile (green) from the same region.

larger amount of $\mathrm{NO}_{2}$ in the lower troposphere and a sharper transition to the free troposphere. In contrast, clean maritime profiles (Fig. 2) have very little $\mathrm{NO}_{2}$ close to the surface. The location of both individual profiles is indicated by the black circles in Fig. 1a.

The different shapes of the $\mathrm{NO}_{2}$ profiles over the domain are reflected in the distribution of airmass factors. As shown in Fig. 3a, very small AMFs are found over polluted regions, as the measurement sensitivity of the satellite decreases towards the surface where most of the $\mathrm{NO}_{2}$ is located in these areas. For the same reason, the AMFs are larger over the ocean where the peak of $\mathrm{NO}_{2}$ is at higher altitudes. The frequency distribution of the individual AMFs computed from the $15-\mathrm{km}$ resolution model simulation is given in the histogram in Fig. 3b. Also shown in the figure are the average airmass factor (1.24) from the distribution of these 361 15$\mathrm{km}$ AMFs (green line) and the airmass factor computed from the domain-average profile (0.94) shown in Fig. 2 (blue line). The latter is more representative of the AMF computed from the input from a coarse resolution CTM. These two different approaches to obtain a single AMF for the full scene differ significantly. Neither of the average AMFs can be considered a good representation of the scene as compared to the distribution of the individual 15-km AMFs. Instead, the distribution is characterized by two distinctly different regimes in the domain. The unpolluted ocean part in the west leads to a cluster of relatively large AMFs around 1.6 and the polluted part over land results in AMFs of less than 1.0.
The histogram shown in Fig. 3b illustrates the basic issue with respect to the calculation of accurate AMFs accounting for heterogeneity of a scene. As the distribution is not compact around a mean value, there is no single representative value for the AMF. Since the spread of AMF values is more than a factor of two, application of a single AMF to this scene will lead to errors of up to $100 \%$. From the inverse relation between airmass factor and vertical column (Eq. 1) it follows that using a single AMF for the whole scene will result in a $100 \%$ overestimation of the retrieved $\mathrm{NO}_{2}$ columns over water and about $50 \%$ underestimation over land.

\subsection{AMF sensitivity to surface reflectance}

Next the sensitivity of the AMF to a more realistic variability of surface spectral reflectance is investigated using albedo values reported by the MODIS land product for this scene. A map of the surface reflectance values used in these AMF calculations is shown in Fig. 4a.

Assuming relatively clear conditions, the indirect diffuse contribution to the albedo can be neglected and the direct hemispheric reflectance from MODIS is used as input for the radiative transfer model. The mean value of the surface spectral reflectance is 0.04 which corresponds well to the Lambert-equivalent reflectance (LER) for this region determined from GOME measurements by Koelemeijer et al. (2003), a dataset often used in tropospheric $\mathrm{NO}_{2}$ retrievals in spite of its well-known problems along coastlines (Popp et al., 2011). However, the MODIS surface reflectance over land varies between 0.01 and 0.08 in our domain. This does not include the effect of surface reflectance anisotropy discussed in Zhou et al. (2010) who found additional variations of up to $40 \%$ for OMI depending on the line of sight viewing angle.

The result of this large variability in surface reflectance is effectively a broadening of the peak at $\mathrm{AMF}=0.8$ in the AMF histogram and shifting to higher values, as can be seen in Fig. 4b. The lower limit of AMFs decreases significantly from 0.7 to 0.4 , resulting from the strongly decreased sensitivity of the satellite measurements for the grid boxes with low albedo (less than 0.025) and high $\mathrm{NO}_{2}$ mixing ratios close to the ground, as found for example in the San Jose area. The enhancement of AMF between 1 and 1.2 occurs in regions with less $\mathrm{NO}_{2}$ pollution and is driven by two effects. First, the surface reflectance increases in many of the land boxes relative to the scenario with constant surface reflectance, which causes the increases of the AMF from about 0.8 to 1.1. Second, the decrease of the surface reflectance in the northern coastal area leads to a decrease of the AMF from 1.4 to 1.15 .

It should be noted that in this sensitivity study, the surface spectral reflectance varies only over land and not over the ocean. While a more homogeneous reflectance above water as compared to the land surface is to be expected, in practice the effects of wind-induced surface roughness, reflection 
(a) AMF Spatial Distribution

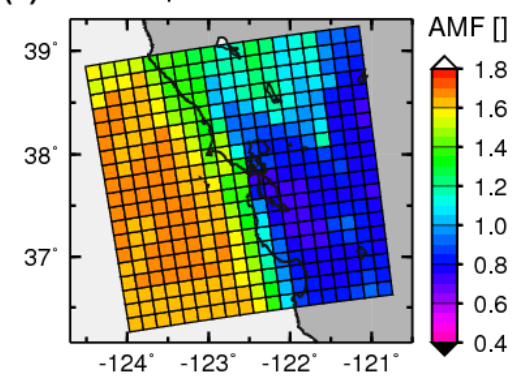

(b) AMF Histogram, Alb: 0.04, no Aerosol

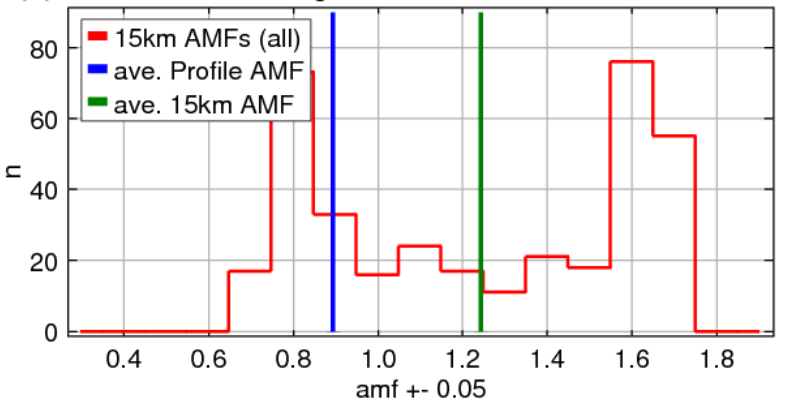

Fig. 3. (a) Map of the airmass factors for tropospheric $\mathrm{NO}_{2}$ using $15 \mathrm{~km}$ WRF-Chem $\mathrm{NO}_{2}$ profiles, constant albedo of 0.04 and no aerosol. (b) AMF distribution within the domain depicted in (a). The histogram (red) shows the frequency distribution of the AMFs for the $15 \mathrm{~km}$ boxes. The two modes represent mainly the separation between clean ocean and polluted land cases. The green line indicates the average AMF. The blue line gives the AMF based on the average profile (Fig. 2).

(a) Black-Sky Albedo

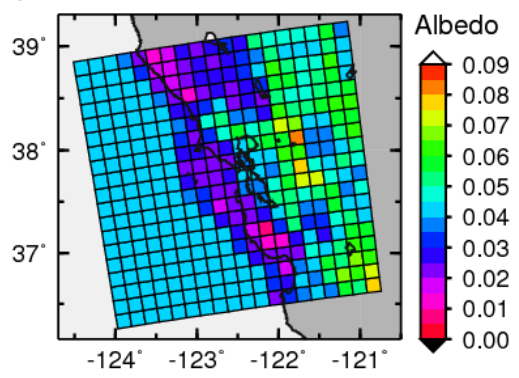

(b) AMF Histogram, const. vs. MODIS Albedo

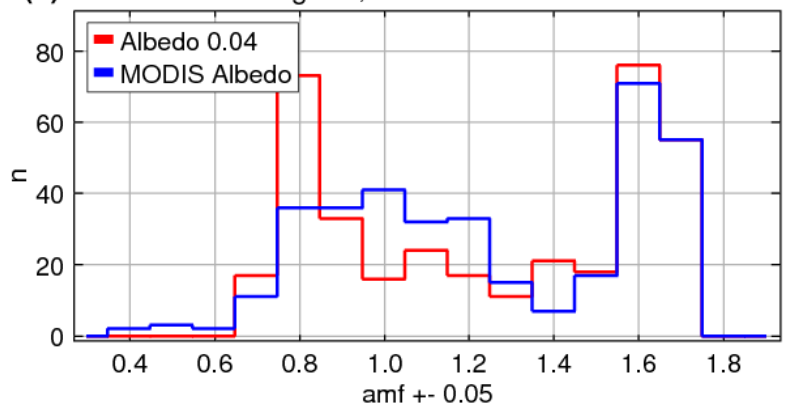

Fig. 4. (a) Spatial distribution of surface reflectance from MODIS at $465 \mathrm{~nm}$ binned to the $15 \mathrm{~km}$ resolution used. Values over the ocean were set to 0.04. (b) The resulting frequency distribution of AMF values in the domain (blue) compared to the one obtained with constant albedo (red, identical to Fig. 3b). Using the variable albedo instead of the constant albedo of 0.04 broadens the left-hand mode (peak at AMF $=0.8$ ) in the AMF histogram to smaller values (0.4) and shifts the peak to larger values (1.0).

off the ocean floor in shallow waters, absorption by oceanic biomass, and sun glint all contribute to variations in effective ocean reflectance which if taken into account would result in a broadening of the right peak in the AMF distribution shown in Fig. 4b.

The overall effect of the variation of the surface spectral reflectance within a single large domain is to increase the spread of AMF values and thereby further increase the range of errors made by application of a single AMF value. The changes of the AMF over land due to the inclusion of the variability of the albedo are about $\pm 30 \%$ on average, with maximum values of $-53 \%$ and $+45 \%$. Depending on which single AMF value is selected, the errors introduced by using only one AMF for the scene can be as large as $100 \%$ for individual pixels if the variability of both the $\mathrm{NO}_{2}$ profile and surface spectral reflectance are combined.

\subsection{AMF sensitivity to aerosol scattering}

In addition to the variations of the $\mathrm{NO}_{2}$ vertical profile and the surface spectral reflectance, the aerosol field also varies over scales much smaller than a standard CTM grid-box. To test the effect of this variation we compared four cases: the reference case with no aerosol, a sensitivity case with a horizontally homogeneous aerosol of optical thickness 0.10 , a second sensitivity case with constant AOT of 1.0 , and a third one with variable AOT derived from the MODIS product (Fig. 5a). For simplicity, we assume that the aerosol layer consists of average continental aerosol as defined by OPAC (Hess et al., 1998) which is moderately absorbing (single scattering albedo 0.92). An average mixing height of $1 \mathrm{~km}$ was selected based on typical shapes of the modelled $\mathrm{NO}_{2}$ profiles (Fig. 2).

Aerosol has essentially three radiative transfer effects on the AMF. First, the aerosol enhances the sensitivity of the satellite measurements to the $\mathrm{NO}_{2}$ above the aerosol layer by enhancing the reflectance below this $\mathrm{NO}_{2}$ layer, and thereby increasing the AMF if the majority of the $\mathrm{NO}_{2}$ is located above the aerosol. Second, the aerosol shields the $\mathrm{NO}_{2}$ in the lower part of the aerosol layer and below as a result of its scattering and absorption. This effect leads to a decrease of the AMF for $\mathrm{NO}_{2}$ below or in the lower part of the 
(a) Aerosol Optical Thickness

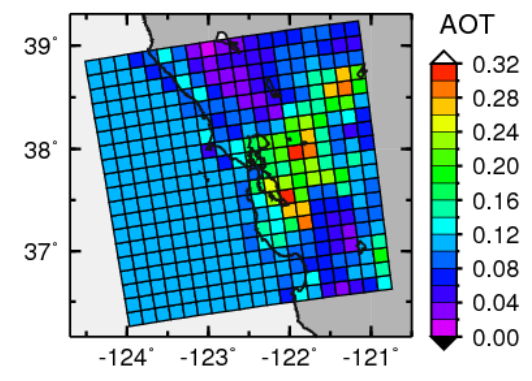

(b) AMF Histogram, Aerosol Dependence

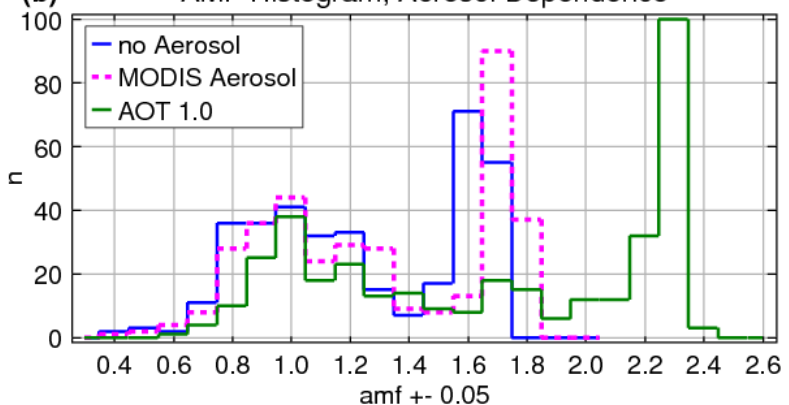

Fig. 5. (a) MODIS derived AOT distribution over land binned to the resolution of this study. The AOT over ocean is held at 0.1 . (b) The AMF distribution derived for the three aerosol scenarios; neglecting aerosol (blue, identical to blue line in Fig. 4b), using the AOT distribution from the image in (a) (pink), and assuming a homogenous AOT of 1.0 (green). The aerosol mixing height was assumed to be $1 \mathrm{~km}$.

aerosol layer. Third, the aerosol increases multiple scattering, thereby enlarging the effective photon path within the aerosol layer. This is an effect which again increases the sensitivity to $\mathrm{NO}_{2}$ in the upper part of the aerosol layer. The combined effect of all three possible aerosol contributions can increase or decrease the AMF depending on the relative vertical distributions of $\mathrm{NO}_{2}$ and aerosol and on the surface reflectance. For the settings selected here, the overall effect of including aerosols will be an increase in AMF. A more detailed discussion of aerosol effects on satellite observations of tropospheric $\mathrm{NO}_{2}$ can be found in Martin et al. (2003), Boersma et al. (2004), and Leitão et al. (2010).

In Fig. 5b, the results are shown for the different aerosol scenarios. The reference case with no aerosol (the blue solid line) is identical to the one shown for variable reflectance in Fig. 4b. The inclusion of an aerosol layer with constant AOT of 1.0 (Fig. 5b, green solid line) results in a strong increase of the AMF over the ocean, where most of the $\mathrm{NO}_{2}$ column resides above the assumed aerosol layer. As discussed above, this corresponds to the aerosol increasing the reflectance below the $\mathrm{NO}_{2}$, resulting in increased AMF. The constant oceanic AOT case is not a realistic scenario and therefore should be interpreted with care. The AMF distribution over land is slightly shifted towards higher AMFs as well, indicating that enhanced photon path length in the boundary layer (multiple scattering) dominates over the shielding effect of aerosol. The case of AOT 1.0 was chosen to mark the result of a more extreme case not uncommon for pollution episodes. The calculation with an aerosol layer of AOT 0.1 (not shown) shows qualitatively the same effect, only the magnitude of the changes is reduced. Introducing spatially varying AOT taken from the MODIS aerosol data (magenta dashed line in Fig. 5b) does not result in significant changes in the AMF. The histogram appears only slightly stretched towards higher AMFs. The mode with the lower AMFs, representing $\mathrm{NO}_{2}$ profiles with higher mixing ratio in the boundary layer, remains effectively unchanged, showing that the aerosol radiative effects of light path enhancement and shielding cancel each other for these relative vertical distributions of aerosol and $\mathrm{NO}_{2}$. This is in agreement with the results for urban scenarios reported in the more detailed aerosol study by Leitão et al. (2010). Cleaner regions (rural areas and ocean) are represented by the mode of higher AMFs. The aerosol has a distinctive effect there as the majority of the $\mathrm{NO}_{2}$ column resides above the assumed aerosol layer and thus the aerosol leads to increased AMF, as discussed above.

Overall, the effect of aerosols on the AMF is surprisingly small for this specific scene and mainly leads to a shift of the AMFs representing less polluted areas to larger values. This is in part related to the assumptions made for this study, in particular that of the vertical mixing of the aerosols and the high single scattering albedo. In cases where the aerosol layer is above the $\mathrm{NO}_{2}$ (e.g. from desert dust), a much stronger shielding is to be expected. More absorbing aerosol (e.g. from biomass burning) would reduce the path length enhancement, also resulting in smaller sensitivity as discussed in Leitão et al. (2010). Last but not least, while the AOT values reported by the MODIS retrieval in this scenario are typical for the region, they are relatively small compared to other polluted parts of the world such as the Eastern US, China, and areas affected by biomass burning. In summary, the effects of spatial variations in AOT on the AMF were found to be relatively small for the particular region studied here, but they are likely to be larger for other situations.

\subsection{Resolution: 15 vs. 90 km}

In Sect. 3.1, the AMFs determined from a high-resolution simulation $(15 \mathrm{~km})$ have been compared to that for a typical CTM resolution $(270 \mathrm{~km})$ where only a single average value for the domain is used. To further investigate the impact of spatial resolution, the distribution of the $15-\mathrm{km}$ AMFs was compared with those for each of the nine $90-\mathrm{km}$ grid boxes using the intermediate resolution WRF-Chem simulation shown in Fig. 1a. In Fig. 6, the histogram of all 15-km 

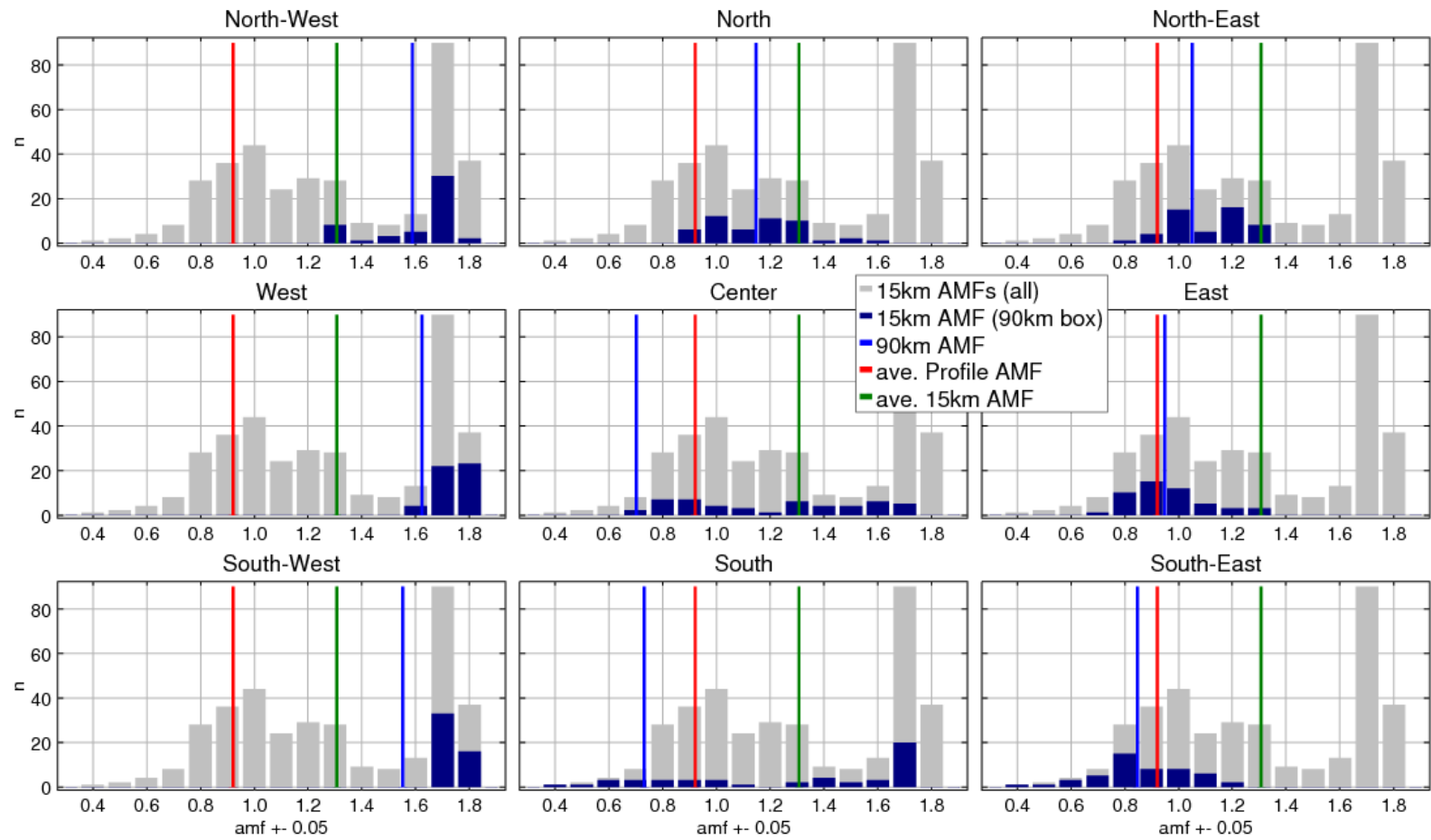

Fig. 6. Comparison of frequency distributions of AMFs for $15 \mathrm{~km}$ boxes in each sub-domain (dark blue histogram) and $15 \mathrm{~km}$ boxes of the whole domain (grey histogram). The light blue lines indicate the AMFs from the profiles in the $90 \mathrm{~km}$ boxes. The nine plots correspond to the nine 90-km sub-domains in Fig. 1a. The red line shows the AMF for the domain average $\mathrm{NO}_{2}$ profile. The green line shows the average AMF of all 15-km AMFs in the domain.

AMFs using variable AOT and variable albedo from MODIS (same as the pink dashed line in Fig. 5b) are shown in grey. The nine different histograms correspond to the nine $90-\mathrm{km}$ subdomains as shown in Fig. 1a. The dark blue histogram is the frequency distribution of those AMFs belonging to the corresponding $90-\mathrm{km}$ grid box. The light blue line indicates the AMF derived using the respective $\mathrm{NO}_{2}$ profile of the 90$\mathrm{km}$ model simulation. Additionally, for comparison, the full domain average $15 \mathrm{~km}$-AMF (green) and the AMF derived using the domain average $\mathrm{NO}_{2}$ profile (red) are also shown Fig. 6.

As can be seen from the figure, the spread in AMFs is reduced in several of the $90-\mathrm{km}$ boxes but not in all. This reflects the remaining inhomogeneity in the smaller boxes, mainly along the coastline. For those boxes with reduced AMF spread, application of the single AMF computed from the $90-\mathrm{km}$ run results in smaller errors than the average AMF for the full region. At least in these examples, a priori data at $90-\mathrm{km}$ resolution would already reduce the errors arising from spatial variability in the $\mathrm{NO}_{2}$ profile. In other cases, the AMFs calculated from the $90-\mathrm{km}$ model run are not close to the average values from the individual $15-\mathrm{km}$ boxes (blue histograms). This is explained by the differences in transport and chemistry between the two model resolutions which impact the $\mathrm{NO}_{2}$ profile in the model, in particular close to the coastline. The effect of model resolution on the $\mathrm{NO}_{2}$ profiles can be large as also discussed in Huijnen et al. (2010), introducing additional uncertainty when using low resolution a priori data in satellite retrievals.

\subsection{Overall uncertainties in $\mathrm{AMFs}$ and $\mathrm{NO}_{2}$ columns}

In the previous sections the impact of the variation in a priori data on the airmass factors was discussed. For most applications, the uncertainty in the retrieved vertical $\mathrm{NO}_{2}$ columns resulting from the use of a priori data from a low-resolution global CTM is a more relevant parameter. While the relative errors of the AMFs can directly be transferred to the $\mathrm{NO}_{2}$ columns (see Eq. 1), the absolute errors depend on the $\mathrm{NO}_{2}$ amount present in the respective sub-pixel. To examine the impact of the AMF variations on satellite retrievals of tropospheric $\mathrm{NO}_{2}$, the uncertainty is determined by first constructing a synthetic slant column from the model $\mathrm{NO}_{2}$ profile and the "true" airmass factor for each $15-\mathrm{km}$ grid box using MODIS surface reflectance and AOT. These slant columns are then converted to "retrieved" vertical columns by applying AMFs based on $\mathrm{NO}_{2}$ profiles, albedo, and AOT at lower spatial resolution. The resulting uncertainties are described by the relationship:

Absolute Uncertainty :

$\Delta \mathrm{VC}_{\mathrm{NO}_{2}}=\left(\frac{\mathrm{AMF}_{15 \mathrm{~km}}}{\mathrm{AMF}_{\mathrm{ave}}}-1\right) \cdot \mathrm{VC}$ 
Table 2. Overview of some AMF error estimates for tropospheric $\mathrm{NO}_{2}$ retrievals from the literature.

\begin{tabular}{|c|c|c|}
\hline Study & Instrument & Relative Error \\
\hline Richter and Burrows (2002) & GOME & Total: $\sim 50 \%$ \\
\hline Martin et al. (2002) & GOME & $\begin{array}{l}\text { Aerosol: }<30 \% \\
\text { Total: }<53 \% \text { (land) }\end{array}$ \\
\hline Boersma et al. (2004) & GOME & $\begin{array}{l}\text { Profile shape }<9 \% \\
\text { Albedo ave: } 15 \% \text { max: }<50 \% \\
\mathrm{NO}_{2} \text { column (polluted): } 35-60 \%\end{array}$ \\
\hline Boersma et al. (2007) & OMI & $\begin{array}{l}\text { As Boersma et al. (2004) but two additional not quantified uncertainties: } \\
\varepsilon_{\mathrm{Ua}}: \text { spatial undersampling of albedo data base } \\
\varepsilon_{\mathrm{Up}}: \text { spatial undersampling of profile shape }\end{array}$ \\
\hline Zhou et al. (2009) & OMI & Topography effects in Alpine region: $5 \%$ in summer, $15-20 \%$ in winter (clear sky) \\
\hline Leitão et al. (2010) & - & Aerosol: up to factor of 2 depending on scenario, $7 \%$ for typical urban scenes \\
\hline Zhou et al. (2010) & OMI & BRDF effects: $0-3 \%$ in July, $0-20 \%$ in November for OMI \\
\hline
\end{tabular}

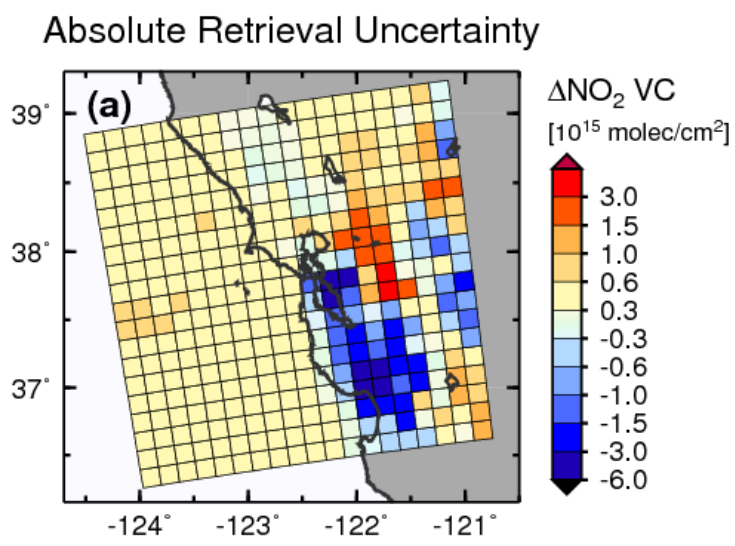

\section{Relative Retrieval Uncertainty}

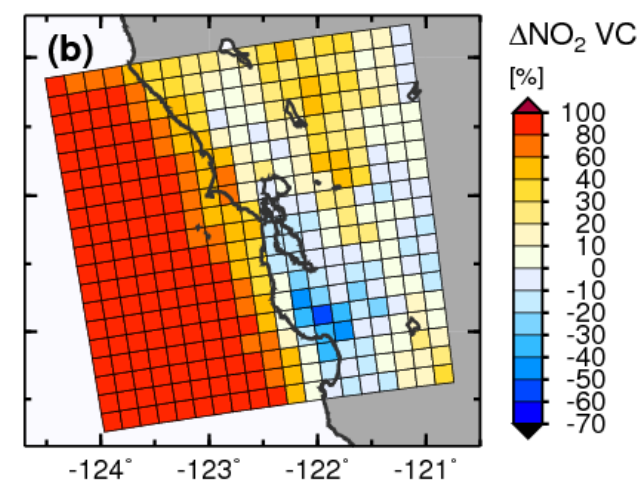

Fig. 7. Simulated retrieval uncertainty introduced by use of a single AMF for the whole domain. (a) Difference between the VC retrieved using a single AMF (based on the average profile for this scene), constant albedo of 0.04, and constant AOT of 0.1, and the true VC from the model. (b) as in (a), but showing relative uncertainties.

Relative Uncertainty :

$\Delta \mathrm{VC}_{\mathrm{NO}_{2}}=\left(\frac{\mathrm{AMF}_{15 \mathrm{~km}}}{\mathrm{AMF}_{\mathrm{ave}}}-1\right) \cdot 100 \%$

In Fig. 7a, the results are shown for the worst case when only the average $\mathrm{NO}_{2}$ profile, a constant albedo of 0.04 , and a constant AOT of 0.1 are used. In this case, the absolute uncertainty in the vertical column due to the AMF varies in the range of $-6 \times 10^{15}$ to $3 \times 10^{15}$ molec $\mathrm{cm}^{-2}$. The largest uncertainties are over land in regions with high $\mathrm{NO}_{2}$ columns, low albedo and high aerosol content. For most of the domain the uncertainties are below $\pm 2 \times 10^{15} \mathrm{molec} \mathrm{cm}^{-2}$. The lower uncertainties however are mostly in regions where the $\mathrm{NO}_{2}$ vertical columns are small, thus the relative uncertainty still is large (Fig. 7b). For example, a $100 \%$ uncertainty is introduced over almost all ocean grid boxes. The maximum uncertainty of the land grid boxes is between $-55 \%$ and $+67 \%$ or $-5.3 \times 10^{15}$ and $+4.6 \times 10^{15}$ molec cm $^{-2}$. The 5th and 95th percentiles are $-21 \%$ and $43 \%$ or $-2.1 \times 10^{15}$ and $1.6 \times 10^{15}$ molec $\mathrm{cm}^{-2}$ respectively. These numbers can be compared to estimates of uncertainties made in previous studies (Table 2). In Fig. 8, similar comparisons are summarised for different scenarios in which the spatial resolution of albedo, aerosols, and $\mathrm{NO}_{2}$ profiles is varied independently. As can be seen, the mean bias is smaller than $5.0 \times 10^{14} \mathrm{molec} \mathrm{cm}^{-2}$ in all cases. The overall spread of values for polluted situations is significantly reduced whenever the albedo used is at high spatial resolution. Neither high resolution profiles, nor high resolution aerosols lead to clear improvements alone. However, the standard deviation for the polluted values is only reduced if in addition to using high resolution albedo and aerosol maps, the $\mathrm{NO}_{2}$ profiles are taken at $90 \mathrm{~km}$ resolution. This illustrates that surface albedo is the first quantity to use at high spatial resolution, but additional introduction of high resolution $\mathrm{NO}_{2}$ profiles is needed to achieve a clear reduction in the standard deviation of the 


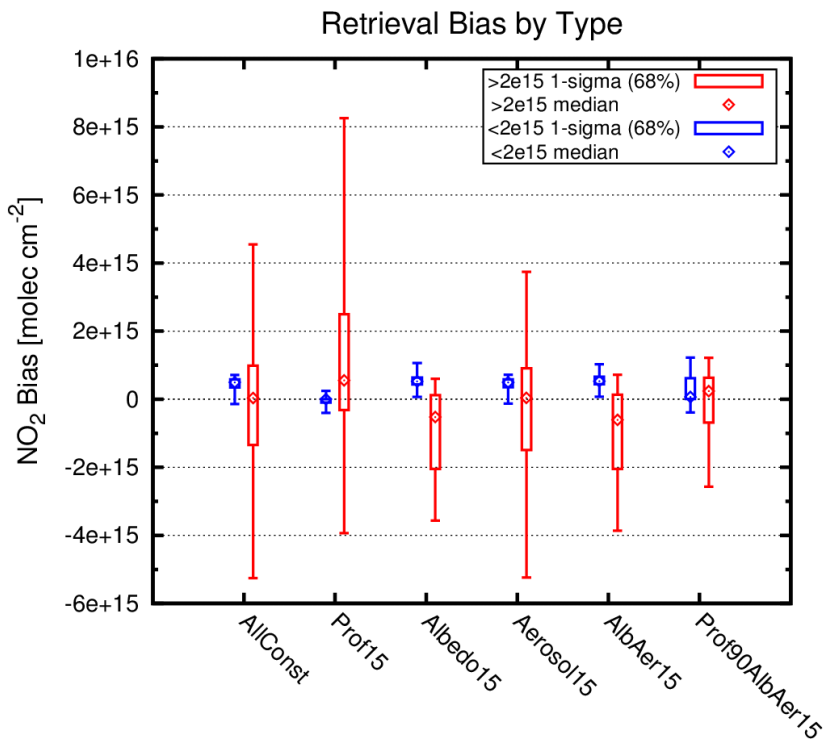

Fig. 8. Retrieval biases inferred from the case study by type of parameter. Shown are the differences between the results obtained when neglecting the spatial variation of one or several parameters to the analysis using the high-resolution input. From left to right, the scenarios are (i) all data at $270 \mathrm{~km}$ resolution, (ii) $\mathrm{NO}_{2}$ profiles at $15 \mathrm{~km}$, aerosol and albedo at $270 \mathrm{~km}$, (iii) albedo at $15 \mathrm{~km}, \mathrm{NO}_{2}$ profiles and aerosol at $270 \mathrm{~km}$, (iv) aerosol at $15 \mathrm{~km}, \mathrm{NO}_{2}$ profiles and albedo at $270 \mathrm{~km},(\mathrm{v})$ albedo and aerosol at $15 \mathrm{~km}, \mathrm{NO}_{2}$ profiles at $270 \mathrm{~km}$, and (vi) albedo and aerosols at $15 \mathrm{~km}$ and $\mathrm{NO}_{2}$ profiles at $90 \mathrm{~km}$ resolution. Blue symbols represent data with an $\mathrm{NO}_{2}$ column less than $2 \times 10^{15}$ molec $\mathrm{cm}^{-2}$, red symbols data with larger columns. Dots are the median, boxes the $1 \sigma$ range and error bars indicate the overall range of values.

values. For situations with low $\mathrm{NO}_{2}$ content (over the ocean and in rural areas), the most important parameter is high resolution $\mathrm{NO}_{2}$ profile shape (see blue symbols in Fig. 8) and improvements in albedo and aerosol resolution have small and not always positive effects.

In general, albedo and clouds are considered to be the major contributors to the error budget. Boersma et al. (2004) give relative errors due to albedo uncertainty of up to $50 \%$, and an average of $15 \%$ for polluted regions. In our study we show that the AMF error due to spatial under-sampling of the surface spectral reflectance alone is about $40 \%$, equivalent to that derived from Boersma et al. (2004) for polluted regions with low albedo. For polluted areas (i.e. annual mean $\mathrm{NO}_{2} \mathrm{VC}>1 \times 10^{15}$ molec $\mathrm{cm}^{-2}$ ), average surface reflectance values of about $4 \%$ for North America, $5 \%$ for Europe and $6 \%$ for China can be estimated using the Koelemeijer database for seasons without snow or monsoon influence. The fact that in these $\mathrm{NO}_{2}$ source regions the column is dominated by the lowermost layers of the $\mathrm{NO}_{2}$ profile and the albedo is of comparable magnitude as in this study highlights the importance of our results beyond the domain of this study.
The importance of the a priori $\mathrm{NO}_{2}$ profiles used in the retrieval has been recognised early and motivated the use of model data as a priori (Martin et al., 2002). In some studies, high-resolution model data was used for the AMFs to better represent the spatial variability (Kim et al., 2006, 2009) or column averaging kernels (Eskes and Boersma, 2003) were applied to remove the effect of low resolution a priori and convert to high resolution (Blond et al., 2007). In a model intercomparison study, the effect of applying averaging kernels from a global and two Regional Air Quality models over Europe was investigated and differences of more than $2 \times 10^{15} \mathrm{molec} \mathrm{cm}^{-2}$ were found for data from August 2008 (Huijnen et al., 2010). For the domain average, the differences were small which was explained by offsetting effects of differences in the boundary layer and free tropospheric $\mathrm{NO}_{2}$ profiles of the models used.

Clearly, the error introduced for an individual pixel by using a single AMF for a heterogeneous $270 \times 270 \mathrm{~km}^{2}$ box can easily exceed the error estimates made in other studies. Errors are smaller for those retrievals using higher resolution surface reflectance, but even in the case with perfect albedo and aerosol, the error from using $\mathrm{NO}_{2}$ profiles at $90 \mathrm{~km}$ resolution can be larger than $2 \times 10^{15} \mathrm{molec} \mathrm{cm}^{-2}$ for individual pixels. This finding is of particular importance as the error has a systematic component and will not always be reduced by averaging data in time. As an example, an emission source which is not resolved in a low resolution a priori data set will lead to consistently wrong AMF under all conditions. In contrast, a surface albedo value from a data base may be too low for a particular region on dry days but too high on wet days leading to changing effects on the AMF. In real applications, the uncertainties can be even larger, as the assumption that the model provides a perfect representation of atmospheric conditions will generally not be fulfilled.

\section{Discussion}

In the previous sections, a case study of the region around San Francisco for a single cloud-free day has been used to demonstrate the impact of the spatial variability in the a priori information used to determine AMF values for the computation of tropospheric vertical column $\mathrm{NO}_{2}$ from measured slant column $\mathrm{NO}_{2}$. The generalization of those results to different seasons or regions is discussed in this section.

\subsection{Single-day vs. monthly-average results}

Generally, satellite retrievals of tropospheric $\mathrm{NO}_{2}$ are only performed for nearly cloud-free conditions. However, since in the chosen domain persistent cloud cover over the ocean is the dominating meteorological condition, the constraint of selecting a cloud free day might have led to exceptional results in the analysis. 


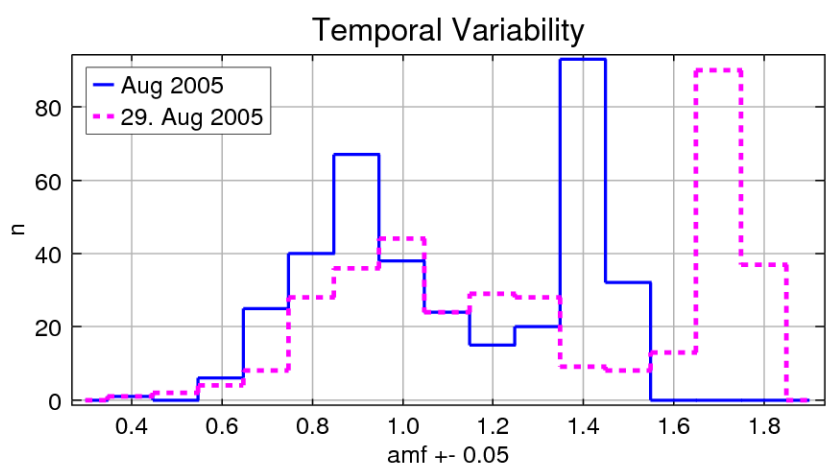

Fig. 9. Comparison of the frequency distribution of $15 \mathrm{~km}$ AMFs for 29 August (pink line, same as in Fig. 5b) and for the AMF averaged over all days in August 2005. The same separation into two major modes, unpolluted ocean and polluted land, is found in the monthly average.

In order to investigate how representative the results of the single-day analysis are, the calculations were repeated for all days in August 2005 using daily-varying $\mathrm{NO}_{2}$ profiles. As in the previous analysis, the effect of clouds was not considered. In Fig. 9 the single day AMF of 29 August 2005 (pink dashed line) and monthly averages (solid blue line) of the AMF in the same region are compared.

The main result of this comparison of monthly average and single-day results is the fact that the bimodal shape of the distribution of the AMFs is preserved, emphasizing that the individual day is not exceptional with respect to the results discussed in the previous sections. The monthly average result is primarily a squeezed version of the single-day results. Considering day-to-day variability in the $\mathrm{NO}_{2}$ profiles, it is clear that the average of a data distribution will generally reduce the spread of the values; however, as can be seen from Fig. 9, it does not lead to a smoothing of the distribution of the AMFs.

While 29 August 2005 might have been exceptional in terms of its meteorology, the main characteristics of the AMF distribution (the range of values and the approximately bimodal distribution) remain the same in monthly-averaged AMFs, indicating that the conclusions drawn hold for summer measurements in this area in general. The similarity of daily and monthly values also highlights the systematic nature of the uncertainties in the $\mathrm{NO}_{2}$ retrievals introduced by inappropriate a priori information and its insensitivity to averaging over longer time periods.

\subsection{Sensitivity to solar zenith angle}

So far, the SZA used was appropriate for summer conditions. In a sensitivity study, we have calculated an additional set of AMFs with the same MODIS AOT and surface reflectance but at a solar zenith angle of $60^{\circ}$. This SZA value corresponds to typical winter conditions at SCIAMACHY

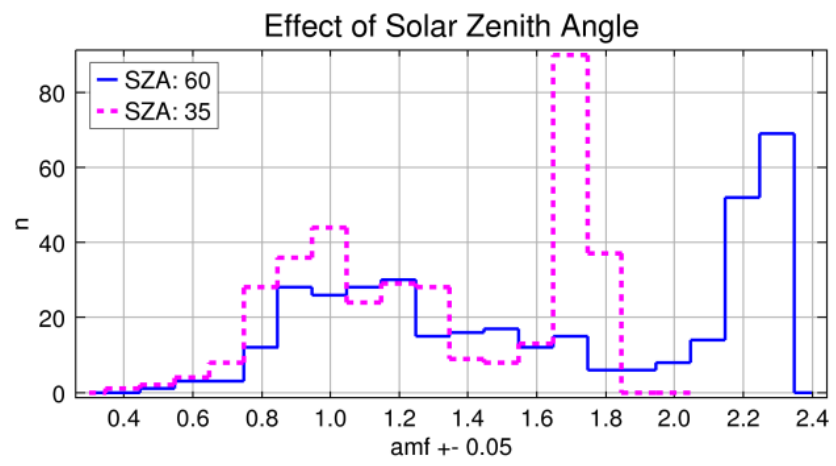

Fig. 10. The histogram of the $15 \mathrm{~km}$ AMFs at solar zenith angle $35^{\circ}$ (summer, pink line, same curve as in Fig. 5b) and at $\mathrm{SZA}=60^{\circ}$ (winter, blue line). At larger SZA, the sensitivity increases, in particular over the ocean (right part of the histogram).

overpass in our domain. The lower sun leads to longer light paths and a corresponding enhancement of the sensitivity, and thus to an increase of the AMFs, as can be seen from Fig. 10. The quasi-bimodal distribution is still conserved. The AMFs over the ocean grow with increasing light path while the width of the land mode of the AMFs is larger as a result of the increased importance of the variability of the a priori data. If the SZA is increased further beyond $75^{\circ}$, the AMFs for polluted areas drop rapidly (not shown). This loss of sensitivity to the boundary layer is the result of the increase in the average scattering height at lower sun. The details of the AMF behaviour with SZA depend on surface albedo and aerosol load, but in general, the effect of AMF variability within one CTM box increases with increasing SZA.

As seasons change, the airmass factors vary not only as result of SZA change, but also for other reasons. The change in solar zenith angle affects the photochemistry and, consequently, the lifetime of $\mathrm{NO}_{2}$, as well as temperature and atmospheric boundary layer height, all of which can have significant effects on the vertical distribution of $\mathrm{NO}_{2}$, i.e. the profile shape. In addition, emissions of $\mathrm{NO}_{\mathrm{x}}$ may vary over the year, which also impacts the $\mathrm{NO}_{2}$ vertical distribution. Last but not least, surface spectral reflectance will also change with season. Therefore, this sensitivity study only covers one aspect of possible seasonal changes, and will have to be extended by a more detailed analysis using appropriate model runs.

\subsection{Other regions}

A change in typical solar zenith angles is also relevant when moving away from the domain of this study towards higher latitudes. More importantly, however, other regions will show different distributions and densities of $\mathrm{NO}_{\mathrm{x}}$ sources. Given the strong impact of the profile variability on small spatial scales, this effect will be the dominating factor. One 
might argue that the impact of small-scale variations is smaller in heavily polluted regions such as parts of Western Europe, the Eastern US or China, where the size of polluted regions is closer to that of a typical CTM grid cell. However, many of the largest $\mathrm{NO}_{\mathrm{x}}$ source regions are relatively close to the coast, as in this study. These transition zones show large AMF uncertainty due to the effect of profile variation on the retrieval. Moreover, studies of long-range transport and chemical change of pollution as well as studies of the lifetime of trace species are often conducted in these coastal regions (e.g. Boersma et al., 2009), highlighting their special scientific interest. In addition to coastal areas, high spatial variations in $\mathrm{NO}_{2}$ profile shape are also expected for isolated $\mathrm{NO}_{\mathrm{x}}$ sources such as large power plants (e.g. Four Corners and San Juan in New Mexico, US; see Kim et al., 2009 for details), cities surrounded by rural areas, interstate highways and sea-based sources such as oil platforms or shipping emissions. For all these types of sources, high-resolution a priori information is needed for accurate satellite retrievals. This is of particular importance in situations where the distribution of emission sources changes over time as, for example, discussed for OMI observations of new power plants in China by Zhang et al. (2009).

In addition to the distribution of the sources and, therefore, the profile variability, the terrain height can have an important impact on retrieval uncertainties as shown by Schaub et al. (2007) and Zhou et al. (2009). By taking the $\mathrm{NO}_{2}$ profiles and surface altitude at high spatial resolution, the terrain effect is accounted for in this study and contributes to the observed AMF variability. The elevation difference between sea and land on the California coastline is not as big as in the Alpine region considered by Zhou et al. (2009), and therefore the elevation difference is not the main reason for the strong sea-land contrast in our particular AMFs. However, the terrain effect does contribute to the large AMF variation over land. The average surface pressure in our domain is $999 \mathrm{hPa}$, with a maximum range of $933 \mathrm{hPa}$ to $1014 \mathrm{hPa}$. A sensitivity analysis based on these two values suggests an impact on the AMFs of less than $5 \%$ for a typical polluted profile shape. This is comparable to the $5 \%$ found in Zhou et al. (2009) for summer conditions in the Alpine region but smaller than the $15-20 \%$ reported for winter. In our study, no significant correlation was found between surface elevation and AMF; thus the observed AMF variability in this study is not likely a result of the topography in our domain. However, many large $\mathrm{NO}_{\mathrm{x}}$ sources are located in regions with high topographic variability, so the impact of small-scale terrain height changes on satellite retrievals must be considered in some cases.

\subsection{Cloud effects}

One of the most important sources of uncertainty in satellite retrievals is the influence of clouds. This was already highlighted in previous studies (Richter and Burrows, 2002; Martin et al., 2003; Boersma et al., 2004, 2007), which estimated the uncertainty in their retrievals to be up to $30 \%$ due to uncertainties in cloud fraction and cloud-top height. As discussed in Popp et al. (2011), the use of low resolution surface reflectance data sets in cloud retrievals can lead to large errors in the retrieved cloud parameters, in particular in coastal areas as the one investigated in this study, resulting in even larger errors locally.

From the high variability in profile shape in our study, we assume an important additional contribution to the error budget with respect to clouds could result from the effects of "model under-sampling". The main effect of clouds is to shield part of the troposphere from the view of the satellite instrument. To correct for this, retrieval approaches often use the independent pixel approximation in which the invisible $\mathrm{NO}_{2}$ in the cloudy part of a pixel is estimated by using the cloud free part of the measurement, the cloud fraction and cloud-top height, and the a priori $\mathrm{NO}_{2}$ profile (e.g. Martin et al., 2002; Boersma et al., 2004). For the scenario discussed in this study, the $\mathrm{NO}_{2}$ profile varies strongly over a domain for which current retrievals often use only one profile. Thus, current cloud algorithms will lead to over-corrections in the cleaner parts of the domain and under-corrections over pollution hot-spots in satellite measurements with high spatial resolution. This situation can be improved by using a priori profiles from higher resolution models. Potentially, these models will also provide more accurate modelling of the specific chemical and dynamical effects in the vicinity of cloud systems such as lightning, convection and modified photolysis rates. Those effects strongly influence the vertical profile shape and therefore need to be included properly in order to retrieve accurate $\mathrm{NO}_{2}$ tropospheric columns in the vicinity of clouds or in partially cloudy pixels.

\section{Summary and conclusion}

The retrieval of tropospheric columns of pollutants such as $\mathrm{NO}_{2}$ from space-based measurements of backscattered solar radiation has undoubtedly been an important breakthrough in our ability to study tropospheric chemistry, air pollution and air quality from the local to the global scale. However, the mathematical retrievals of tropospheric trace gas amounts from these top-of-atmosphere measurements require knowledge of a variety of parameters in addition to the satellitemeasured radiances. This information is currently taken in part from measurements, e.g. for surface albedo, but also from global atmospheric models, e.g. for the vertical trace gas profiles. Global CTMs that provide the needed a priori input for the global determination of tropospheric columns of $\mathrm{NO}_{2}$ typically have poorer spatial resolution than the ground scene of current satellite observations. As the spatial resolution of the measurements increases with better 
instrumentation, a priori information is needed at similar resolutions to avoid smoothing and misrepresentation errors in the data product. However, in most current retrievals this is not yet the case.

In this study, the uncertainties introduced by variations in the shape of the vertical $\mathrm{NO}_{2}$ profile, albedo and aerosol on the retrieval of tropospheric $\mathrm{NO}_{2}$ columns over an area representative of the typical spatial resolution of the current generation of CTMs $\left(270 \times 270 \mathrm{~km}^{2}\right)$ used to generate the a priori datasets have been investigated. The San Francisco area was selected as a test case as it has large variability in all input parameters, but similar situations are expected in many industrialised regions close to coastlines. To estimate the spatial variability of the a priori data, the regional WRFChem model was used to simulate the atmospheric chemistry at two different resolutions $(90 \mathrm{~km}$ and $15 \mathrm{~km})$. These model datasets then provided the $\mathrm{NO}_{2}$ profiles used in the AMF calculations. Similarly high spatial resolution data from MODIS were used to provide surface spectral albedo and aerosol datasets at the same resolution as the modelled $\mathrm{NO}_{2}$ profiles.

Locally, differences of up to a factor of two in both directions were found between calculations using the spatially resolved input data and the worst case, where all a priori data was taken at the $270 \times 270 \mathrm{~km}^{2}$ resolution. Maximum errors could be reduced by approximately a factor of two by using surface albedo at high resolution, illustrating the large importance of this quantity in particular for polluted regions. However, the 1- $\sigma$ range of individual biases could only be reduced to less than $1.0 \times 10^{15} \mathrm{molec}^{-2}$ when the spatial resolution of the profile shape of tropospheric $\mathrm{NO}_{2}$ used was improved to $90 \times 90 \mathrm{~km}^{2}$ (see Fig. 8). As the region studied is characterised by two distinct regimes (one over ocean and the other over land), the resulting bi-modal distribution of AMFs cannot be represented well by a single average AMF. Using a priori information on a $90 \times 90 \mathrm{~km}^{2}$ grid reduced the spread of values in most parts of the domain, indicating that this input data resolution would already constitute a significant improvement in the retrieval. In our test case, the impact of aerosol on the AMF was less than $15 \%$, but in cases of high AOT (1.0) it can be up to a factor of two. As the assumptions made for the aerosol composition and vertical distribution were oversimplified in this study, the effects of aerosols need to be studied in more detail to fully assess their importance for the retrieval.

The uncertainties introduced by inaccurate a priori information are to a large extent linked to geolocation. Thus the retrieval errors are not random but rather systematic, with similar biases in all measurements taken under similar conditions at specific locations. This implies that averaging in time will not help much to reduce this type of error. Averaging the satellite data in space, on the other hand, should reduce the error as the decreased resolution approaches that of the a priori data used. One implication is that resolution errors are expected to be most relevant for current-generation retrieval algorithms applied to the higher resolution instruments (such as OMI) and less problematic for lower resolution data, e.g. from the GOME instrument.

Since the uncertainties derived from this sensitivity study are large, it is necessary to consider the impact of the results of this study on previous studies and applications using satellite-derived $\mathrm{NO}_{2}$ columns. Direct application of the results shown here to previous work is not easy as many recent studies use slightly better resolved $\mathrm{NO}_{2}$ profiles and often much better resolved terrain height and surface spectral reflectance data than assumed in the worst case scenario here.

However, it is clear that the most valid results arise from studies where actual spatial variability is significantly lower than that of the satellite measurements and the a priori information used for the AMF calculations. Conversely, the studies most affected by these uncertainties are those using individual satellite measurements or data averaged at high spatial resolution. Of particular concern are validation studies using one-to-one comparisons to in-situ data or point measurements, high spatial resolution air quality analyses, and comparisons to regional models of high spatial resolution. Previous studies investigating relative changes or trends of tropospheric $\mathrm{NO}_{2}$ over larger areas (Bertram et al., 2005; Richter et al., 2005; van der A et al., 2006) are much less affected by the uncertainties reported here, as both spatial averaging and the use of relative changes tends to cancel the effects of small-scale spatial variability in the input data. Studies inverting satellite measurements to $\mathrm{NO}_{\mathrm{x}}$ emissions (e.g. Konovalov et al., 2008; Martin et al., 2006), usually adjust the resolution of the measurements to the model grid and should, therefore, also be less affected. Some recent regional studies (Blond et al., 2007; Kim et al., 2006, 2009) have explicitly calculated AMFs at high resolution or used averaging kernels and therefore, at least for the $\mathrm{NO}_{2}$ profiles, account for the full spatial variability.

In summary, a priori data of similar spatial resolution is needed to fully exploit the high spatial resolution of current and future satellite measurements of tropospheric constituents. Surface spectral reflectance is a key quantity and progress has been made in the direction of data bases with better spatial resolution (Kleipool et al., 2008; Popp et al., 2011). Even with these data sets in place, using lower spatial resolution CTMs to provide the a priori information in particular the trace gas profile for the AMF calculations results locally in large systematic errors. Therefore, high resolution a priori data should be used whenever possible. As the spatial resolution of satellite instruments further improves, the ability of models to properly represent individual plumes, emissions and clouds at the time of satellite overpass with an accuracy of a few kilometres is a challenge probably best addressed with a full integration of model, retrieval, and satellite data. 
Acknowledgements. MODIS data was provided by NASA through the MODIS web pages. The authors wish to acknowledge funding support from the University of Bremen, the European Union through the CITYZEN project (grant no. 212095), and NOAA's Health of the Atmosphere research program. We thank F. Boersma and an anonymous reviewer for their helpful comments and suggestions.

Edited by: T. von Clarmann

\section{References}

Beirle, S., Platt, U., Wenig, M., and Wagner, T.: Weekly cycle of $\mathrm{NO}_{2}$ by GOME measurements: a signature of anthropogenic sources, Atmos. Chem. Phys., 3, 2225-2232, doi:10.5194/acp-32225-2003, 2003.

Beirle, S., Platt, U., von Glasow, R., Wenig, M., and Wagner, T.: Estimate of nitrogen oxide emissions from shipping by satellite remote sensing, Geophys. Res. Lett., 31, L18102, doi:10.1029/2004GL020312, 2004.

Bertram, T., Heckel, A., Richter, A., Burrows, J. P., and Cohen, R.: Satellite measurements of daily variations in soil $\mathrm{NO}_{\mathrm{x}}$ emissions, Geophys. Res. Lett., 32, L24812, doi:10.1029/2005GL024640, 2005.

Blond, N., Boersma, K. F., Eskes, H. J., van der A, R. J., Van Roozendael, M., De Smedt, I., Bergametti, G., and Vautard, R.: Intercomparison of SCIAMACHY nitrogen dioxide observations, in situ measurements and air quality modeling results over western Europe, J. Geophys. Res., 112, D10311, doi:10.1029/2006JD007277, 2007.

Boersma, K. F., Eskes, H. J., and Brinksma, E. J.: Error Analysis for Tropospheric $\mathrm{NO}_{2}$ Retrieval from Space, J. Geophys. Res., 109, D04311, doi:10.1029/2003JD003962, 2004.

Boersma, K. F., Eskes, H. J., Veefkind, J. P., Brinksma, E. J., van der A, R. J., S neep, M., van den Oord, G. H. J., Levelt, P. F., Stammes, P., Gleason, J. F., and Bucsela, E. J.: Near-real time retrieval of tropospheric $\mathrm{NO}_{2}$ from OMI, Atmos. Chem. Phys., 7, 2103-2118, doi:10.5194/acp-7-2103-2007, 2007.

Boersma, K. F., Jacob, D. J., Eskes, H. J., Pinder, R. W., Wang, J., and van der A, R. J.: Intercomparison of SCIAMACHY and OMI tropospheric $\mathrm{NO}_{2}$ columns: Observing the diurnal evolution of chemistry and emissions from space, J. Geophys. Res., 113, D16S26, doi:10.1029/2007JD008838, 2008.

Boersma, K. F., Jacob, D. J., Trainic, M., Rudich, Y., DeSmedt, I., Dirksen, R., and Eskes, H. J.: Validation of urban $\mathrm{NO}_{2}$ concentrations and their diurnal and seasonal variations observed from the SCIAMACHY and OMI sensors using in situ surface measurements in Israeli cities, Atmos. Chem. Phys., 9, 3867-3879, doi:10.5194/acp-9-3867-2009, 2009.

Bovensmann, H., Burrows, J. P., Buchwitz, M., Frerick, J., Noel, S., Rozanov, V. V., Chance, K. V., and Goede, A.: SCIAMACHY: Mission objectives and measurement modes, J. Atmos. Sci., 56, 127-150, 1999.

Burrows, J., Weber, M., Buchwitz, M., Ladstätter-Weißenmayer, A., Richter, A., DeBeek, R., Hoogen, R., Bramstedt, K., Eichmann, K.-U., Eisinger, M., and Perner, D.: The global ozone monitoring experiment (GOME): Mission concept and first scientific results, J. Atmos. Sci., 56, 151-175, 1999.
Callies, J., Corpaccioli, E., Eisinger, M., Lefebvre, A., Munro, R., Perez-Albinana, A., Ricciarelli, B., Calamai, L., Gironi, G., Veratti, R., Otter, G., Eschen, M., and van Riel, L.: GOME2 ozone instrument on-board the European METOP satellites, in: Weather and Environmental Satellites, Vol. 5549 of Proceedings of the Society of Photo-Optical Instrumentation Engineers (Spie), Spie-Int Soc Optical Engineering,, edited by: Von der Haar, T. and Huang, H., Bellingham, USA, 60-70 pp., 2004.

Celarier, E. A., Brinksma, E. J., Gleason, J. F., Veefkind, J. P., Cede, A., Herman, J. R., Ionov, D., Goutail, F., Pommereau, J.P., Lambert, J.-C., van Roozendael, M., Pinardi, G., Wittrock, F., Schönhardt, A., Richter, A., Ibrahim, O. W., Wagner, T., Bojkov, B., Mount, G., Spinei, E., Chen, C. M., Pongetti, T. J., Sander, S. P., Bucsela, E. J., Wenig, M. O., Swart, D. P. J., Volten, H., Kroon, M., and Levelt, P. F.: Validation of Ozone Monitoring Instrument nitrogen dioxide columns, J. Geophys. Res., 113, D15S15, doi:10.1029/2007JD008908, 2008.

Cohen, J. E., Small, C., Mellinger, A., Gallup, J., and Sachs, J.: Estimates of coastal populations, Science, 278, 1209-1213, 1997.

Eskes, H. J. and Boersma, K. F.: Averaging kernels for DOAS totalcolumn satellite retrievals, Atmos. Chem. Phys., 3, 1285-1291, doi:10.5194/acp-3-1285-2003, 2003.

Franke, K., Richter, A., Bovensmann, H., Eyring, V., Jöckel, P., Hoor, P., and Burrows, J. P.: Ship emitted $\mathrm{NO}_{2}$ in the Indian Ocean: comparison of model results with satellite data, Atmos. Chem. Phys., 9, 7289-7301, doi:10.5194/acp-9-7289-2009, 2009.

Frost, G. J., McKeen, S. A., Trainer, M., Ryerson, T. B., Neuman, J. A., Roberts, J. M., Swanson, A., Holloway, J. S., Sueper, D. T., Fortin, T., Parrish, D. D., Fehsenfeld, F. C., Flocke, F., Peckham, S. E., Grell, G. A., Kowal, D., Cartwright, J., Auerbach, N., and Habermann, T.: Effects of changing power plant $\mathrm{NO}_{\mathrm{x}}$ emissions on ozone in the eastern United States: Proof of concept, J. Geophys. Res., 111, D12306, doi:10.1029/2005JD006354, 2006.

Grell, G. A., Peckham, S. E., Schmitz, R., McKeen, S. A., Frost, G., Skamarock, W. C., and Eder, B.: Fully coupled "online" chemistry within the WRF model, Atmos. Environ., 39, 6957-6975, doi:10.1016/j.atmosenv.2005.04.027, 2005.

Hains, J. C., Boersma, F. K., Kroon, M., Dirksen, R. J., Cohen, R. C., Perring, A. E., Bucsela, E., Volten, H., Swart, D. P. J., Richter, A., Wittrock, F., Schoenhardt, A., Wagner, T., Ibrahim, O. W., van Roozendael, M., Pinardi, G., Gleason, J. F., Veefkind, J. P., and Levelt, P.: Testing and improving OMI DOMINO tropospheric NO2 using observations from the DANDELIONS and INTEX-B validation campaigns, J. Geophys. Res., 115, D05301, doi:10.1029/2009JD012399, 2010.

Hess, M., Koepke, P., and Schult, I.: Optical Properties of Aerosols and clouds: The software package OPAC, B. Am. Meteorol. Soc., 79, 831-844, 1998.

Huijnen, V., Eskes, H. J., Poupkou, A., Elbern, H., Boersma, K. F., Foret, G., Sofiev, M., Valdebenito, A., Flemming, J., Stein, O., Gross, A., Robertson, L., D’Isidoro, M., Kioutsioukis, I., Friese, E., Amstrup, B., Bergstrom, R., Strunk, A., Vira, J., Zyryanov, D., Maurizi, A., Melas, D., Peuch, V.-H., and Zerefos, C.: Comparison of $\mathrm{OMI} \mathrm{NO}_{2}$ tropospheric columns with an ensemble of global and European regional air quality models, Atmos. Chem. Phys., 10, 3273-3296, doi:10.5194/acp-10-3273-2010, 2010. 
Kim, S. W., Heckel, A., McKeen, S. A., Frost, G. J., Hsie, E. Y., Trainer, M. K., Richter, A., Burrows, J. P., Peckham, S. E., and Grell, G. A.: Satellite-observed US power plant $\mathrm{NO}_{\mathrm{x}}$ emission reductions and their impact on air quality, Geophys. Res. Lett., 33, L22812, doi:10.1029/2006GL027749, 2006.

Kim, S.-W., Heckel, A., Frost, G. J., Richter, A., Gleason, J., Burrows, J. P., McKeen, S. A., Hsie, E.-Y., Granier, C., and Trainer, M.: $\mathrm{NO}_{2}$ columns in the western United States observed from space and simulated by a regional chemistry model and their implications for $\mathrm{NO}_{\mathrm{x}}$ emissions, J. Geophys. Res., 114, D11301, doi:10.1029/2008JD011343, 2009.

Kleipool, Q. L., Dobber, M. R., de Haan, J. F., and Levelt, P. F.:, Earth surface reflectance climatology from 3 years of OMI data, J. Geophys. Res., 113, D18308, doi:10.1029/2008JD010290, 2008.

Koelemeijer, R. B. A., de Haan, J. F., and Stammes, P.: A database of spectral surface reflectivity in the range $335-772 \mathrm{~nm}$ derived from 5.5 years of GOME observations, J. Geophys. Res., 108, 4070, doi:10.1029/2002JD002429, 2003.

Konovalov, I. B., Beekmann, M., Burrows, J. P., and Richter, A.: Satellite measurement based estimates of decadal changes in European nitrogen oxides emissions, Atmos. Chem. Phys., 8, 26232641, doi:10.5194/acp-8-2623-2008, 2008.

Leitão, J., Richter, A., Vrekoussis, M., Kokhanovsky, A., Zhang, Q. J., Beekmann, M., and Burrows, J. P.: On the improvement of $\mathrm{NO}_{2}$ satellite retrievals - aerosol impact on the airmass factors, Atmos. Meas. Tech., 3, 475-493, doi:10.5194/amt-3-475-2010, 2010.

Levelt, P., Van den Oord, G., Dobber, M., Malkki, A., Visser, H., de Vries, J., Stammes, P., Lundell, J., and Saari, H: The ozone monitoring instrument, IEEE T. Geosci. Remote, 44(5), 10931101, 2006.

Levy, R. C., Remer, L. A., and Dubovik, O.: Global aerosol optical properties and application to Moderate Resolution Imaging Spectroradiometer aerosol retrieval over land, J. Geophys. Res., 112, D13210, doi:10.1029/2006JD007815, 2007a.

Levy, R. C., Remer, L. A., Mattoo, S., Vermote, E. F., and Kaufman, Y. J.: Second-generation operational algorithm: Retrieval of aerosol properties over land from inversion of Moderate Resolution Imaging Spectroradiometer spectral reflectance, J. Geophys. Res., 112, D13211, doi:10.1029/2006JD007811, 2007b.

Martin, R. V., Chance, K., Jacob, D. J., Kurosu, T. P., Spurr, R. J. D., Bucsela, E., Gleason, J. F., Palmer, P. I., Bey, I., Fiore, A. M., Li, Q., Yantosca, R. M., and Koelemeijer, R. B.: An improved retrieval of tropospheric nitrogen dioxide from GOME, J. Geophys. Res., 107, 4437-4456, 2002.

Martin, R. V., Jacob, D. J., Chance, K., Kurosu, T. P., Palmer, P. I., and Evans, M. J.: Global inventory of nitrogen oxide emissions constrained by space-based observations of $\mathrm{NO}_{2}$ columns, J. Geophys. Res., 108(D17), 4537, doi:10.1029/2003JD003453, 2003.

Martin, R. V., Sioris, C. E., Chance, K., Ryerson, T. B., Bertram, T. H., Wooldridge, P. J., Cohen, R. C., Neuman, J. A., Swanson, A., and Flocke, F. M.: Evaluation of space-based constraints on global nitrogen oxide emissions with regional aircraft measurements over and downwind of eastern North America, J. Geophys. Res., 111, D15308, doi:10.1029/2005JD006680, 2006.

McKeen, S., Wilczak, J., Grell, G., Djalalova, I., Peckham, S., Hsie, E.-Y., Gong, W., Bouchet, V., Menard, S., Moffet, R.,
McHenry, J., McQueen, J., Tang, Y., Carmichael, G. R., Pagowski, M., Chan, A., Dye, T., Frost, G., Lee, P., and Mathur, R: Assessment of an ensemble of seven real-time ozone forecasts over eastern North America during the summer of 2004, J. Geophys. Res., 110, D21307, doi:10.1029/2005JD005858, 2005.

Ordóñez, C., Richter, A., Steinbacher, M., Zellweger, C., Nüß, H., Burrows, J. P., and Prévôt, A. S. H.: Comparison of 7 years of satellite-borne and ground-based tropospheric $\mathrm{NO}_{2}$ measurements around Milan, Italy, J. Geophys. Res., 111, D05310, doi:10.1029/2005JD006305, 2006.

Popp, C., Wang, P., Brunner, D., Stammes, P., Zhou, Y., and Grzegorski, M.: MERIS albedo climatology for FRESCO $+\mathrm{O}_{2}$ A-band cloud retrieval, Atmos. Meas. Tech., 4, 463-483, doi:10.5194/amt-4-463-2011, 2011.

Richter, A. and Burrows, J. P.: Retrieval of Tropospheric $\mathrm{NO}_{2}$ from GOME measurements, Adv. Space Res., 29, 1673-1683, 2002.

Richter, A., Eyring, V., Burrows, J. P., Bovensmann, H., Lauer, A., Sierk, B., and Crutzen, P. J.: Satellite Measurements of $\mathrm{NO}_{2}$ from International Shipping Emissions, Geophys. Res. Lett., 31, L23110, doi:10.1029/2004GL020822, 2004.

Richter, A., Burrows, J., Nüß, H., Granier, C., and Niemeier, U.: Increase in tropospheric nitrogen dioxide over china observed from space, Nature, 437, 129-132, 2005.

Rozanov, A., Rozanov, V., Buchwitz, M., Kokhanovsky, A., and Burrows, J. P.: SCIATRAN 2.0 - a new radiative transfer model for geophysical applications, Adv. Space Res., 36(5), 10151019, 2005.

Russell, A. R., Valin, L. C., Buscela, E. J., Wenig, M. O., and Cohen, R. C.: Space-based Constraints on Spatial and Temporal Patterns of $\mathrm{NO}_{\mathrm{x}}$ Emissions in California, 2005-2008, Environ. Sci. Technol., 44(9), 3608-3615, doi:10.1021/es903451j, 2010.

Salomon, J., Schaaf, C. B., Strahler, A. H., Gao, F., and Jin, Y.: Validation of the MODIS Bidirectional Reflectance Distribution Function and Albedo Retrievals Using Combined Observations from the Aqua and Terra Platforms, IEEE T. Geosci. Remote, 44, 1555-1565, doi:10.1109/TGRS.2006.871564, 2006.

Schaaf, C. B., Gao, F., Strahler, A. H., Lucht, W., Li, X., Tsang, T., Strugnell, N. C., Zhang, X., Jin, Y., Muller, J.-P., Lewis, P., Barnsley, M., Hobson, P., Disney, M., Roberts, G., Dunderdale, M., Doll, C., d'Entremont, R., Hu, B., Liang, S., Privette, J. L., and Roy, D. P.: First Operational BRDF, Albedo and Nadir Reflectance Products from MODIS, Remote Sens. Environ., 83, 135-148, 2002.

Schaub, D., Brunner, D., Boersma, K. F., Keller, J., Folini, D., Buchmann, B., Berresheim, H., and Staehelin, J.: SCIAMACHY tropospheric $\mathrm{NO}_{2}$ over Switzerland: estimates of $\mathrm{NO}_{\mathrm{x}}$ lifetimes and impact of the complex Alpine topography on the retrieval, Atmos. Chem. Phys., 7, 5971-5987, doi:10.5194/acp-7-59712007, 2007.

van $\operatorname{der}$ A, R. J., Peters, D. H. M. U., Eskes, H., Boersma, K. F., Van Roozendael, M., De Smedt, I., and Kelder, H. M.: Detection of the trend and seasonal variation in tropospheric $\mathrm{NO}_{2}$ over China, J. Geophys. Res., 111, D12317, doi:10.1029/2005JD006594, 2006.

van der A, R. J., Eskes, H. J., Boersma, K. F., van Noije, T. P. C., Van Roozendael, M., De Smedt, I., Peters, D. H. M. U., and Meijer, E. W.: Trends, seasonal variability and dominant $\mathrm{NO}_{\mathrm{x}}$ source derived from a ten year record of $\mathrm{NO}_{2}$ measured from space, J. 
Geophys. Res., 113(D4), D12317, doi:10.1029/2007JD009021, 2008.

Zhang, Q., Streets, D. G., and He, K.: Satellite observations of recent power plant construction in Inner Mongolia, China, Geophys. Res. Lett., 36, L15809, doi:10.1029/2009GL038984, 2009.

Zhou, Y., Brunner, D., Boersma, K. F., Dirksen, R., and Wang, P.: An improved tropospheric $\mathrm{NO}_{2}$ retrieval for OMI observations in the vicinity of mountainous terrain, Atmos. Meas. Tech., 2, 401-416, doi:10.5194/amt-2-401-2009, 2009.
Zhou, Y., Brunner, D., Spurr, R. J. D., Boersma, K. F., Sneep, M., Popp, C., and Buchmann, B.: Accounting for surface reflectance anisotropy in satellite retrievals of tropospheric $\mathrm{NO}_{2}$, Atmos. Meas. Tech., 3, 1185-1203, doi:10.5194/amt-3-11852010, 2010. 